\title{
Cleaning of Coal Energy Used in Igcc Plants
}

\section{Vijay Anand}

\begin{abstract}
This paper proposes an advanced technology-based system that is suitable for cleaning the coal energy used in integrated gasification combined cycle (IGCC) plants. In present era, the coal used in several power plants as a raw material emits huge amount of harmful gases and causes air pollution in the environment. Therefore, this paper focus on developing an advanced technology-based coal cleaning process that helps in gasification of coal and improves the efficiency of the power generation.
\end{abstract}

Keywords- IGCC plants, coal gasification, Coal pyrolysis, power generation.

\section{INTRODUCTION}

In the reply of growing pollution globally, the advanced form of power generation is demanded. Since in past year coals are used in almost every region of the country for producing electricity [1]. The utilization of coal in thermal power plants emits huge amount of harmful gases and causes air pollution [2]. These air pollutions further cause cancer and other types of diseases in human body, therefore it is requiring to minimize the air pollution produced by such type of coals [3], [4]. The air pollution is basically causing due to the burning of coals in such type of thermal power plant. Thus, filtration of coal is in huge demand now a days so that clean and pure electric energy is produced by the utilization of coal without causing much air pollution. In the process of filtration of coal, the fuel is converted from solid to liquid [5]. With the help of this process more efficient power is generated with less air pollution and eliminates harmful gases like CO2, NOx, SOx and PM. The gasification take place inside the filtration unit with passing required amount of oxygen in it [6]. The temperature requires for conversion from solid to liquid is as high as $800 \mathrm{oC}$ and the pressure required during this pressure is about 25 bar. The following reaction takes place during the process of gasification or filtration as shown below:

\section{Thermal Decomposition:}

$$
\mathrm{HC}+\mathrm{Heat}=\mathrm{H}_{2}+\mathrm{C}+\text { Organics }
$$

2. Reaction with Oxygen:

$$
\mathrm{HC}+\mathrm{O}=\mathrm{H}_{2}+\mathrm{CO}+\text { Heat }
$$

3. Reaction with Steam:

$$
\mathrm{HC}+\mathrm{H}_{2} \mathrm{O}+\mathrm{Heat}=3 / 2 \mathrm{H}_{2}+\mathrm{CO}
$$

4. Reaction with Hydrogen:

$$
\mathrm{HC}+\mathrm{H}_{2}=\mathrm{CH}_{4}+\text { Heat }
$$

\section{SYSTEM DESCRIPTION OF PROPOSED METHOD \& RESULTS}

"Coal pyrolysis is a cleaning process of coal in which initial step is coal gasification" [7]. In this process of coal pyrolysis firstly, the coal materials are desiccated by warm

Revised Manuscript Received on 14 September, 2019.

Vinay Anand, Department of Electrical Engineering, Sanskriti University, U.P. India.(Email: sanpubip@ gmail.com) gases and after desiccating coal materials the temperature start rising above $350 \mathrm{oC}$. Hydrogen rich gases, phenol, tars and oils are some products of pyrolysis [8]. Char is the remainder of pyrolysis that contains residual mineral and carbon matter. These char particle start reacting when the temperature reaches above $750 \mathrm{oC}$ and at this temperature gasification took place [9]. Temperature, pressure, heat rate, particle size and coal rank are some parameters that affects coal pyrolysis process.

Table 1: Primary products produced by fossil fuel gasification

\begin{tabular}{llll}
\hline Product & \multicolumn{2}{c}{ Primary product } & \multirow{2}{*}{$\begin{array}{l}\text { Secondary } \\
\text { product }\end{array}$} \\
\cline { 2 - 4 } & Operating plant & Planned plant & \\
\hline Electricity & 35 & 25 & 6 \\
Hydrogen & 11 & 1 & 11 \\
Ammonia & 34 & 3 & 1 \\
Syngas & 14 & 1 & 2 \\
Methanol & 12 & 1 & 11 \\
Oxy-chemicals & 22 & 0 & 1 \\
Carbon dioxide & 7 & 0 & 5 \\
Others (FT & 25 & 4 & 0 \\
liquids fuel gas) & & & \\
Total & 160 & 35 & 37 \\
\hline
\end{tabular}

Table 1: shows the primary products that are produced by fossil fuel gasification. It represents the pyrolysis products such as electricity, hydrogen, ammonia, syngas, methanol, oxy-chemicals, carbon dioxide, liquids and fuel gas. The primary products comes under operating plant and planned plant [10].

Basically, the prolysis of coal is performed in two stages. In first stage the temperature is between $500 \mathrm{oC}$ to $600 \mathrm{oC}$ and in this case very few amount of gas is progressed. In second stage the temperature is between $1000 \mathrm{oC}$ to 1600 $\mathrm{oC}$ and during these range of temperatures the gas is fragmented off. 


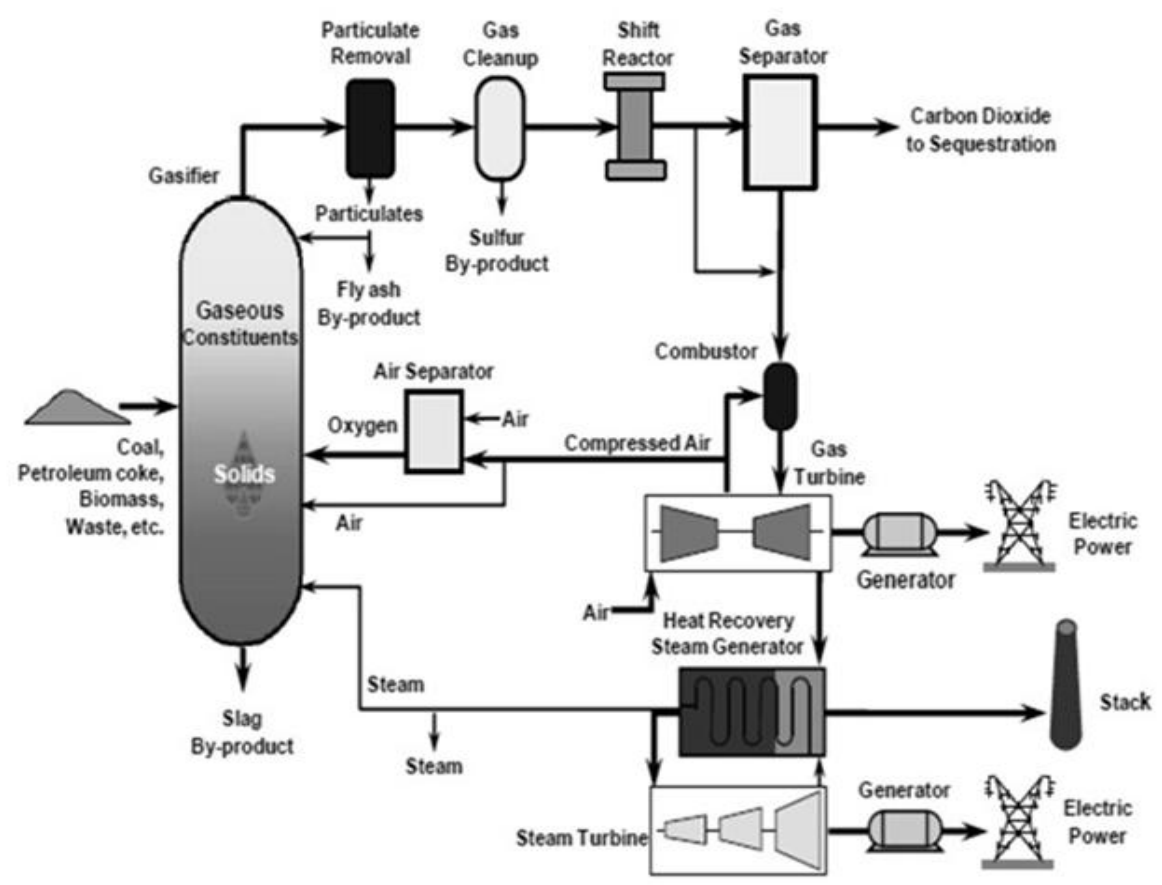

Fig. 1: IGCC plants with carbon capture

It is stated that there are maintly two types of integrated gasification combined cycle (IGCC) plants. "An integrated gasification combined cycle (IGCC) is a technology that uses a high pressure gasifier to turn coal and other carbon based fuels into pressurized gas - synthesis gas. It can then remove impurities from the syngas prior to the power generation cycle" [11], [12].

Fig. 1 shows the integrated gasification combined cycle plants with carbon capture. In this plant firstly the coal is inserted in the combustion chamber and from other side sufficient amount of oxygen is provided for supporting combustion process. The slag by product is removed out and the gaseous constituents passes through particulate removal chamber in which the fly ash is seperated. Further the gas passes through shift reactor to separate impurities and makes the gas clean and waste $\mathrm{CO} 2$ goes to confiscation. After purification process the pure form of gas goes to closed loop gas turbine and gas turbine is coupled with electric generator to generate electricity as a final output.

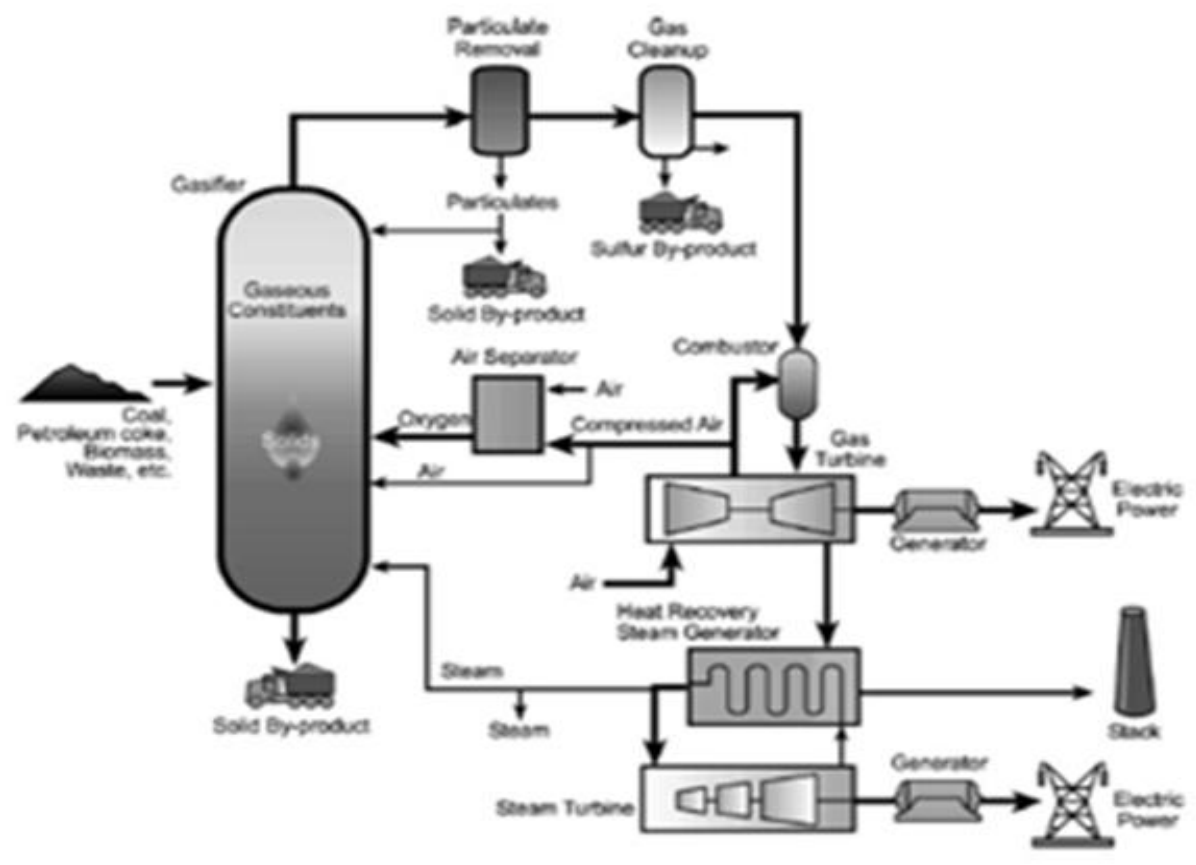

Fig. 2: IGCC plants without carbon capture

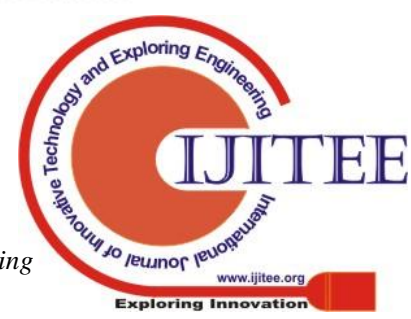


Fig.2 represents the integrated gasification combined cycle (IGCC) plants without carbon capture. The main difference between these two plant is that in this plant, no shift reactor is provided for cleaning the gas and separate $\mathrm{CO} 2$ into sequestration. In this plants the impure form of gas is removed through a tower.

\section{CONCLUSION}

This paper provides a detail awareness against the air pollution caused by the utilization of coal. In this paper the integrated gasification combined cycle (IGCC) plants with carbon capture and without carbon capture is compared. It is concluded that after coal gasification the coal is utilized in a most efficient manner without emitting much harmful gases and air pollution in the environment.

\section{REFERENCES}

1. D. Rao and T. Gouricharan, "Proximate analysis of coal," in Coal Processing and Utilization, 2016.

2. P. Vairakannu, "Clean coal technologies," in Sustainable Utilization of Natural Resources, 2017.

3. M. Kanniche, R. Gros-Bonnivard, P. Jaud, J. ValleMarcos, J. M. Amann, and C. Bouallou, "Precombustion, post-combustion and oxy-combustion in thermal power plant for CO2 capture," Appl. Therm. Eng., 2010.

4. A. Prabhakar, A. K. Sadhukhan, B. Kamila, and P. Gupta, "Modeling and Experimental Studies on CO2 Gasification of Coarse Coal Char Particle," Energy and Fuels, 2017.

5. Y. $\mathrm{Wu}, \mathrm{S}$. Wu, J. Gu, and J. Gao, "Differences in physical properties and $\mathrm{CO} 2$ gasification reactivity between coal char and petroleum coke," Process Saf Environ. Prot., 2009.

6. H. Liu, H. Zhu, M. Kaneko, S. Kato, and T. Kojima, "High-temperature gasification reactivity with steam of coal chars derived under various pyrolysis conditions in a fluidized bed," in Energy and Fuels, 2010.

7. A. K. Sadhukhan, P. Gupta, T. Goyal, and R. K. Saha, "Modelling of pyrolysis of coal-biomass blends using thermogravimetric analysis," Bioresour. Technol., 2008.

8. M. Ozturk and I. Dincer, "Integrated Gasification Combined Cycles," in Comprehensive Energy Systems, 2018.

9. A. Pyrolysis and A. Pyrolysis, "Abstracts," Fuel Energy Abstr., 2014.

10. D. L. Brink, "Gasification," in Organic Chemicals from Biomass, 2018.

11. F. Emun, M. Gadalla, T. Majozi, and D. Boer, "Integrated gasification combined cycle (IGCC) process simulation and optimization," Comput. Chem. Eng., 2010.

12. R. W. Breault, "Gasification processes old and new: A basic review of the major technologies," Energies. 2010. 